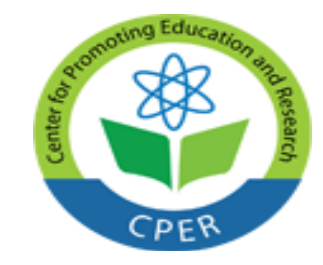

\title{
Going Social: Implications for Facebook Usage in Education
}

\author{
Iyana Mason \\ University of St. Francis \\ USA \\ Bonnie J. Covelli, Ed.D. ${ }^{1}$ \\ Assistant Professor \\ Chair \\ Graduate and Degree Completion Professional Studies/Incubator \\ College of Business and Health Administration \\ University of St. Francis \\ 500 Wilcox St. \\ Joliet, IL 60435 \\ Phone: 815-740-5071 \\ E-mail: bcovelli@stfrancis.edu \\ USA
}

\section{Abstract}

Social media has played a critical role in information sharing, revolutionizing the manner in which professional and personal communication takes place. Nevertheless, many educators still primarily rely on traditional forms of communication to engage parents. Social media sites such as Facebook offer schools the opportunity to connect with parents using non-traditional, two-way communication tools. The purpose of the study was to identify parents' preferred means of communicating and to determine the effectiveness of Facebook to facilitate parent-teacher engagement. Data was collected from parents whose students were enrolled in regular and honors freshman algebra classes in a high-poverty, high-minority suburban high school. Frequency distribution was used to examine parents' communication preferences and contingency analysis was used to examine parents' support for Facebook. Findings from this study showed that while parents prefer a variety of traditional and non-traditional communication tools, they do not yet support parent-teacher communication via Facebook.

\section{Keywords: social media, school communication, secondary education, Parental involvement}

\section{Introduction}

Forms of communication are constantly evolving and changing, and the introduction of the internet has had a tremendous impact on the way in which organizations are communicating with their stakeholders. To state that the internet has made a profound impact on the global society would be an understatement. Mobile technology has heralded in a hyper-connected era in the Information Age in which people have greater access to contact one another and retrieve information about anything at any time. Much of this is due to the proliferation and increasing affordability of mobile devices and increases in home internet adoption. In a 2012 Pew Research Center survey, $44 \%$ of smartphone owners admitted that their phone saved them time because they were able to access any information they need at all times (Smith, 2012). Nearly 50\% of adult mobile phone owners slept with their phones

\footnotetext{
${ }^{1}$ Corresponding Author: Bonnie J. Covelli, Ed.D.
} 


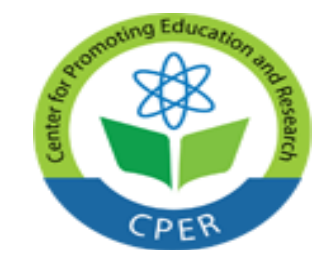

VOL: 5, ISSUE: 2

February/2019

E-ISSN: 2469-6501

(C) Center for Promoting Education and Research (CPER) USA

WwW.cpernet.org

nearby so they would not miss calls, texts, or alerts and nearly $30 \%$ indicated their phone was something they could not fathom living without (Pew Research Center, 2014). Among the plethora of activities that mobile devices can be used for, one of the most popular is accessing social media. According to Martinez-Aleman (2014), adults spend $63 \%$ of their time on mobile devices using social media.

Undoubtedly social media has become ingrained in the fabric of contemporary society, revolutionizing the way in which communication takes place. While hundreds of social media sites exist, none has the mass appeal in the global community like Facebook. Founded in 2006 by then-Harvard student Mark Zuckerberg, Facebook is the second most visited website in the world (IACP Center for Social Media, 2015). It is a web-based platform in which users connect to people and businesses by sharing, commenting, and liking photos, videos, and status updates, and playing games. More than 4,000 photos are posted every second and more than 293,000 status updates are posted on Facebook every 60 seconds (IACP Center for Social Media, 2015). If all Facebook users in the world were a country, it would be among the largest in the world.

Years ago, corporations recognized the value of social media sites to connect with consumers for a variety of reasons product promotion and community relations. These sites are also increasingly being used by government entities, non-profit organizations, colleges and universities, and other institutions for a variety of reasons related to information sharing, marketing, advocacy, and fundraising. In the realm of public education; however, social media adoption is far less advanced and not nearly as embraced as in other industries. Cuban (2001) suggested that public education has not kept pace with technological advances over the past quarter-century. Notwithstanding the general public's proclivity to use social media, educators generally refrain from using these communication tools either in the classroom or to reach parents. Notably, educators are increasingly using social media to connect with one another and share resources. However, can these tools be useful to connect to parents?

Due to the impact of parental involvement in student outcomes, it is important for school personnel to understand parents' preferred means of contact to solicit their participation in activities that support students' learning both at school and at home. Teacher-parent communication remains difficult at any grade level because of cultural differences and career and familial responsibilities. At the high school level, school-home communication is confounded by students' age. Parents are more willing to provide independence and believe that their contribution is not as important as their children grow in age (Ouimette, Feldman, \& Tung, 2006; Oxley, 2013). Furthermore, many parents may lack the skills needed to help their children with their schoolwork. Lesser educated parents may direct their attention away from their children's education because of their own academic inadequacies (DePlanty, 2007). Conversely, teenagers may discourage their parents' participation due to their tendency to become easily embarrassed by their parents and heightened sensitivity to authority. As they continue on their path to adulthood, teenagers also increasingly seek opportunities to exert autonomy and gain a semblance of independence. The purpose of this study was to determine parents' communications preferences and the appropriateness and effectiveness of parent-teacher communication via Facebook, a non-traditional communication method.

\section{Literature Review}

\section{Communication and Parental Involvement}

Epstein (2001) suggested that parents and educators regarded communication as the most important component of parent involvement. Similarly, other studies (Bokony, Whiteside-Mansell, \& Swindle, 2013; Bridgemohan, van Wyk, \& van Staden, 2005) also concluded that communication was of critical importance to programs that engaged parents in school activities. Bridgemohan et al. (2005) asserted that parents had limited opportunities to initiate communication with schools. When the opportunity was offered, Bokony et al. (2013) found that parent-teacher communication could be more meaningful than polite conversations about unimportant matters. 


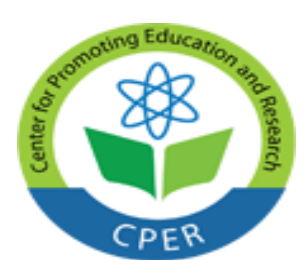

Halsey (2005) acknowledged that although teachers tend to send institutional messages, parents prefer personalized invitations for involvement. According to Halsey (2005), parents perceive these messages to be announcements whereas teachers regard this messaging to be invitational. Receiving detailed invitations that clearly delineate their role and responsibilities encourages parents to become involved (Halsey, 2005).

Communication efforts can help create an inviting environment that encourages parents to participate. By incorporating individualized rather than institutionalized invitations, teachers can enhance relations with parents. Specific invitations from teachers for involvement have been identified as one of the motivating factors for parental involvement at all levels because it highlights the value that teachers attribute to parents' contributions (Green et al., 2007).

A growing number of educators in school districts across the country are using social media, in various ways, to bridge the gap between school and home. Eric Sheninger, an award-winning former principal of a New Jersey High School, noted that "since society as a whole is actively using social media, it only makes sense to connect with my community through these means" (Ferriter,2011). Social media provides schools with communication tools that enable them to reach and create a sense of community among a wider, more diverse group of families.

\section{Social Media as a Communication Tool}

The creation of social media dates back to more than half a century. One of the first social networking sites, called Open Diary, was launched in 1959 and allowed users to come together in an online community (Kaplan \& Haenlein, 2010). In the years since the earliest social media sites were created, much has changed with regard to the capability of these sites and the individuals who access them. The prevalence of social media continues to increase among the general public. Social media adoption rates and pervasive rates of mobile telephone ownership offer the opportunity for the rapid dissemination of information to large audiences. Educational institutions are capitalizing on the opportunities presented by social media, embracing these tools albeit at a much slower rate than other industries, to connect with students and their families.

Essential elements of social media. Kietzman, Hermiens, McCarthy, and Silvestre (2011) developed seven essential components of social media which include the following: presence, relationships, identity, conversations, sharing, reputation, and groups. Presence allows users to know the extent to which other users are presented on various platforms. As an illustration, a teacher or principal could include their Facebook name or Twitter handles in the classroom or school-specific newsletters and on class websites to inform students and parents about their social media presence. Relationships represent the presence of formal, structured connections between users and acquaintances (or the lack thereof). The creation and maintenance of relationships that can be regulated through requests and permission levels are what provides value to using these platforms. For instance, a job seeker who launches a profile on LinkedIn (a social media site for professionals), yet never completes their work experience and fails to reach out to current and former colleagues has defeated the purpose of joining the site. Identity refers to the manner in which users reveal personal information and their preferences, dislikes, and other information that expresses their individuality and personality.

Conversations represent the extent to which users communicate with others. The nature and type of conversation will vary based on the platform utilized and its intended purpose. Twitter, a micro blogging site, may not be the most appropriate choice for a writer known for verbose language choices. Sharing refers to the exchange and dissemination of content. Reputation includes the trust of users in one another. As the name suggests, groups represent the extent what users can form communities to widen their networks.

Connecting with others. Sharing information about one's identity and personal life includes some of the many ways in which social media has changed modern culture. People are willing to share their private identity, 


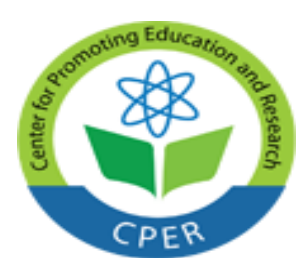

thoughts, and personal feelings in very public ways. It has become commonplace, and now socially acceptable, for people to post content of intimate moments (births, marriages, marital strife, deaths) with people they do and do not know personally. While people are reluctant to meet strangers in the offline world, there are social media users who readily accept connection requests from strangers.

Use in the classroom. Initially social media, like many other technological devices in the field of education, was treated like a distraction. In so much as pagers and cell phones were initially regarded as nuisances, social media was regarded as a nuisance rather than an opportunity. Although social media usage is commonplace among students and their parents (and grandparents for that matter), elementary and secondary school educators remain reluctant to use social media for educational purposes. A study conducted by the University of Phoenix (2014) found that while $80 \%$ of K-12 teachers use social media for personal or professional purposes, only $18 \%$ actually used social media in the classroom. Among the $82 \%$ of study respondents who indicated they had not yet integrated social media, 55\% said they were not interested in doing so in the future. Nevertheless, higher education faculty members are increasingly utilizing social media to enhance teaching, learning, and professional development. A survey conducted by Babson Research Group and Pearson found that $41 \%$ of higher education faculty members utilized social media tools in the classroom (Moran, Seaman, Tinti-Kane, 2011). Nearly 80\% indicated that digital technology increased their communication with students.

Several reasons may explain the greater social media adoption rates of higher education faculty as compared to elementary and secondary teachers. First, due to the ages and maturity levels of the students they serve, higher education faculty members have fewer legal concerns regarding their communication with students. Second, professors have greater academic freedom to utilize pedagogical practices without fear of professional punishment. Lastly, there are fewer institutional barriers that hinder implementation as social media sites are less likely to be blocked on college campuses. Due to the size of higher education institutions, they likely have more technical support staff that can help faculty members integrate this technology in their work.

There is a paucity of information readily available on the use of social media in the school setting. In a rare study of the implementation of social media at the high school level, Mourlam (2013) examined the implementation of a Facebook group in a social studies course to ascertain student and instructor perceptions on the use of social media in the learning environment. Though it was used inconsistently by the teacher involved in the study, $79 \%$ of students indicated that Facebook was a useful classroom tool (Mourlam, 2013).

Empirical research on the usage of social media by teachers in the classroom is mixed, scarce, and limited primarily to higher education (Ranieri, Manc, \& Fini, 2012; Towner \& Munoz, 2011). Mazer, Murphy, and Simonds (2009) examined the effects of teacher self-disclosure via Facebook on college students' motivation, learning, and classroom climate. Results from that study indicated that students who accessed the Facebook profiles of teachers with higher levels of self-disclosure reported more positive classroom experiences, higher levels of perceived teacher trustworthiness, and higher levels of motivation to learn. Haspels (2008) also found that Facebook usage had a positive effect on the faculty-student relationship. Conversely, Towner and Munoz (2011) in their study of the connection between college students and their professors found that students were not open to personal communication with faculty on Facebook. Nearly $70 \%$ of students were in favor of instructors using Facebook for posting announcements and class schedules (Towner \& Munoz, 2011). Findings from a study of college students demonstrated that students felt Facebook was not an appropriate tool for academic usage and consequently used it primarily for socialization with other students rather than with their professors (Mendez, Curry, Mwavita, Kennedy, Weinland, \& Bainbridge, 2009)

The dearth of research on social media usage as it relates to elementary and secondary teachers may be attributed to the scarcity with which K-12 educators actually integrate social media tools in their pedagogical 


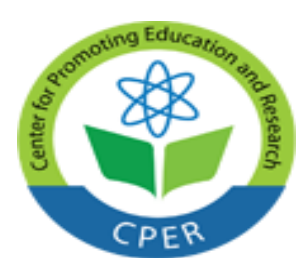

practices. Furthermore, empirical evidence has not yet definitively proven a positive relationship between teachers' social media usage and students' academic performance. Increasingly, schools are turning to social media for community relations purposes related to passing bond referendums, increasing student enrollment, and increasing parental involvement, among other concerns. Actually, a recent study highlighted the need for schools to include social media in crisis management plans. Researchers from Clemson and Western Kentucky universities examined more than 5,000 social media posts during active shooter incidents in September 2014 (Coyne, 2015). Results from this study found that misinformation flooded social media following these incidents and consequently, it was necessary for schools to incorporate the accurate release on information via social media in crisis communication planning efforts to dispel false information. While schools are gradually recognizing the value of social media platforms to create and maintain relationships with stakeholders, teachers rarely receive training on how to use social media tools effectively. Ironically, teachers are utilizing social media to learn not only how to use these platforms, but also to connect with other educators throughout the globe to build and maintain their professional learning networks.

Educator reluctance to use. Rather than simply blaming teachers for being resistant to the adoption and integration of technological changes, Hosman and Cvetanoska (2013) argued that the technological innovation movement has failed over the past 20 years because administrators and policymakers felt the mere introduction of technology would result in changes. Instead, they attested that teachers should be treated as stakeholders who play a critical role in determining the success of technology in the classroom instead of being relegated to participants as an afterthought. Educators may be reluctant to utilize social media in their professional practices for several key reasons.

First, there is a common misconception that social media is only used for socialization and entertainment purposes. Facebook was created by a then-college student as a means to communicate with other college students. As a result, educators are reluctant to use the site though it may have educational benefits. Rutherford (2010) observed that the negative public perception regarding Facebook as a place for gossiping and bullying initially deterred the use of the site by the academic community.

Second, as Lewis (2010) noted, the creation of social media sites has grown exponentially on a near-constant basis, with rules governing their usage constantly changing. Time-strapped professionals may be too busy to learn and stay current on these sites. As users of these sites could attest, their interfaces, features, and functions are continuously updated. Tutorials that help users understand how to use social media become out-dated quickly after being posted online. Additionally, there is uncertainty on how to use these tools strategically.

Third, boundaries between educators' professional and personal lives have become increasingly blurred in this digital age. Many educators are reluctant to join in the world of social media because they are concerned with privacy issues. Various high-profile incidents have occurred across the nation in which educators have been disciplined and/or terminated for text, photos, and videos they shared regardless if the content was posted on professional or personal, public or private profiles during non-work hours.

American citizens are all guaranteed freedom of speech under the First Amendment. School employees (whether public or private) are held to a much more stringent standard of behavior on social media. Freedom of speech issues notwithstanding, school personnel have been disciplined and terminated for social media posts that do not necessarily violate school board policies but have demonstrated lapses in professional judgment that call into question their ability to serve students.

A Miami-area high school principal was recently dismissed from his position and was reassigned to other duties after expressing his support of the police officer involved in the now infamous McKinney, Texas pool party incident (in which the officer slammed a bikini-clad African-American teenager to the ground) on Facebook 


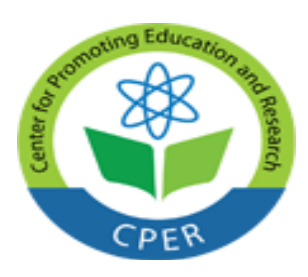

(Wagner, 2015). The following day, a Texas elementary school teacher was fired after posting a racist rant on Facebook, spurred by the McKinney incident, in which she advocated racial segregation and claimed Blacks are "causing all the problems" (Silverstein, 2015).

In addition to the legal implications, there are ethical considerations that hinder educators' usage of social media sites as well. Unfortunately, there are educators who utilize the pseudo-anonymity of social media sites to sexually exploit students. Rather than being accused of inappropriate online communication with students, there are many educators who believe that it is easier to simply refrain altogether from delving into social media.

Lastly, demographic factors may also impact social media adoption. Technology adoption is related to age and teacher experience levels. There is an inverse relationship between technology adoption and age. As technology adoption decreased age increased. Kotrlik and Redman (2009) found that more experienced teachers were less likely to use technology than those teachers with less experience.

\section{Methods}

This study employed the techniques associated with survey quantitative methodology. Purposeful and convenience sampling were utilized to recruit participants for this study. A year-long core course was chosen because it was assumed that parents would be more likely to communicate with their child's teacher in a core course rather than an elective course.

The school where the study was conducted is one of two schools in a two-high school district. In addition to career and technical education classes, the school offers honors and Advanced Placement classes to students. Overall the population at the school, which serves 1,820 students, is 71 percent low-income, 59 percent AfricanAmerican, 19 percent Hispanic, 16 percent Caucasian, 1 percent Asian, 4 percent multiracial, and 1 percent American Indian/Pacific Islander.

Study participants included parents of students at a public, comprehensive high school in suburban Cook County, Illinois. Specifically, these parents had freshmen (ninth graders) enrolled in regular and honors algebra classes. Participants were approached to complete the survey the week after the second semester parent-teacher conferences were held. Invitations to complete the survey were provided to 107 parents - all of whom had students enrolled in one of the selected algebra teacher's classes.

A modified version of the Illinois 5 Essentials Survey, developed by the University of Chicago Consortium on School Research, was used as the survey instrument. The 5 Essentials Survey was validated by more than 20 years of research in public schools in Chicago (UChicago Impact, n.d.). Based on this research, the 5 Essentials Survey examines five critical elements of successful schools: 1) effective leaders; 2) involved families; 3) collaborative teachers; 4) ambitious instruction; and 5) supportive environment. The 5 Essentials Survey includes 120 questions and 22 measures related to the aforementioned five categories using Likert scales to measure effectiveness, satisfaction, and frequency.

While the 5 Essentials Survey has separate surveys for parents, teachers, and students, only questions from the parent survey were used for this study. Specifically, questions regarding parents' involvement with schoolrelated activities and communication with teachers were derived from the 5 Essentials Survey. Since the 5 Essentials Survey does not include questions related to social media usage, the study utilized questions about the frequency of Facebook usage, length of time per session, and the primary purpose of usage from a study conducted by Tyson (2009) on the influence of social networking on communication.

The survey included 44 items and 5 measures on a closed-ended questionnaire that included Likert, dichotomous, and frequency questions about parents' self-reported assessments of their school involvement, schoolhome communication preferences, and Facebook usage. The response format for the 4-point Likert-type scale 


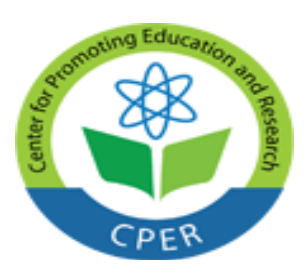

questions including the following answer choices: not effective, somewhat effective, effective, and very effective. Choices for frequency questions included never, rarely, occasionally, usually, and always.

Face validity was achieved by a panel of parents of adolescents completing the survey instrument. Content validity was achieved by having a group of district administrators and classroom teachers, with 40 combined years of educational experience, evaluating the extent to which the survey accurately measured parental participation activities. Based on feedback from parents and subject-matter experts, certain questions were refined for the sake of brevity and clarity.

The data was entered into an Excel spread sheet and SPSS was used for quantitative data analysis (Adams, Infeld, \& Wulff, 2011). Descriptive and inferential statistical techniques, including frequency distribution and cross tabulation were used in this analysis.

\section{Results}

The study population included 54 parents $(n=54)$ of freshmen (ninth grade) students enrolled in a public, comprehensive high school in south suburban Chicago.

One of the primary questions guiding this research was: What tools do parents consider to be the most effective to communicate with them? Frequency distribution was used to answer this question. Parents were asked to rate the effectiveness of electronic and non-electronic, traditional, and non-traditional communication tools to contact them on a scale of not effective, somewhat effective, effective, and very effective. Specifically, the study asked about Facebook, email, text messaging, phone call, notes, newsletter, mobile app, and postal mail.

Overall, the majority of parents did not feel that Facebook was an effective way to contact them. Parents' effectiveness ratings of Facebook as a means to contact them are as follows: not effective (60\%), somewhat effective $(23 \%)$, effective $(15 \%)$, and very effective $(2 \%)$. While parents were not in favor of contact through Facebook, they were amenable to other forms of electronic communication with teachers.

Seven out of ten parents claimed that email was a very effective way to reach them, $15 \%$ said it was effective, $9 \%$ said it was somewhat effective, and $4 \%$ said it was not effective. The majority of parents were also willing to communicate with teachers via text. Among respondents, 56\% claimed that texting was an effective way for teachers to reach them, $17 \%$ claimed it was effective, $15 \%$ claimed it was somewhat effective, and $13 \%$ claimed it was not effective. On the other hand, most parents indicated that mobile apps were not effective way to reach them. One-third of respondents indicated that mobile apps were either very effective (11\%) or effective $(23 \%)$ means of communicating with them. Since the study did not specifically ask respondents about their ownership of a smartphone, it cannot be determined whether their effectiveness rating of this medium is because of their lack of smartphones or their lack of knowledge about mobile apps that can be used to communicate. Ironically, more than 1,600 users parents, students, teachers and staff, and community members have downloaded the mobile app for the school (the research site) selected for this study.

Parents' effectiveness ratings of phone calls are as follows: very effective (7\%), effective (24\%), somewhat effective $(6 \%)$. None of the respondents suggested that phone calls were an ineffective means of communication. It should be noted, however, that the study did not distinguish between landline home and mobile telephones in the survey. Landline phones may be on their way to extinction but mobile telephone usage is pervasive among the entire population of American adults. Data suggests that as of 2014, 90\% of American adults own a cellular telephone, and 64\% are smartphone owners (Pew Research Center, 2014).

Despite declines in overall mail volume and increases in junk mail, parents indicated that postal mail was an effective way to reach them. However, parents' preferences regarding postal mail varied greatly. Based on the 


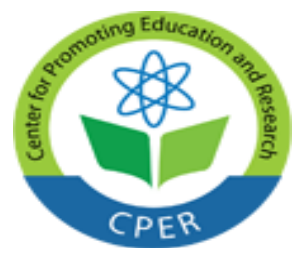

VOL: 5, ISSUE: 2

February/2019

https://ijbassnet.com/

E-ISSN: 2469-6501

(c) Center for Promoting Education and Research (CPER) USA

WWW.cpernet.org

responses, $30 \%$ of respondents indicated that postal mail was very effective, $34 \%$ said it was effective, $17 \%$ said it was somewhat effective, and $19 \%$ said it was not effective. This finding was surprising because the school has a high mobility rate. Data from the Illinois State Board of Education (ISBE) indicates that the school has a $25 \%$ mobility rate, which is the \% age of students who transfer in and out of the school (ISBE, 2015).

Although parents were open to receiving postal mail, they were less receptive to receiving other forms of written communication. Among respondents, 30\% suggested that newsletters were not effective, $4 \%$ suggested they were somewhat effective, $20 \%$ said they were effective and $9 \%$ said they were very effective. In contrast, there was a higher $\%$ age of parents who expressed that notes were a very effective or effective method of communication. Nearly one-quarter of the sample (24\%) claimed that notes were very effective, more than one-third (37\%) claimed notes were effective, nearly one-fifth (19\%) said they were somewhat effective, and one-fifth (20\%) said they were not effective.

The mean for all of the questions ranked parents' communication preferences based on their indication if the tool was very effective or effective. The table below shows how parents indicated their communication preferences.

Table 1

Parents' Effectiveness Ratings of Communication Tools

\begin{tabular}{lc}
\hline Tool & Number of Parents Rated Very Effective and Effective \\
\hline Phone call & 51 \\
Email & 47 \\
Text message & 39 \\
Postal mail & 34 \\
Notes & 33 \\
Mobile app & 18 \\
Newsletter & 16 \\
Facebook & 9 \\
\hline
\end{tabular}

Another question that guided this study was: What is the relationship between parents who support Facebook communication and their involvement in school-related activities at home? Contingency tables were created to examine the four variables related to this measure. Chi-square analysis was used to address this question. The results did not indicate statistically significant differences between parental support of teacher-initiated Facebook communication and the frequency that parents did any of the following with their child at home: supervised their child as they completed their homework $(\mathrm{p}=1)$; helped their child with their homework $(\mathrm{p}=0.9)$; talked about the school day $(\mathrm{p}=0.9)$; and worked on activities that supported their learning $(\mathrm{p}=0.9)$. Findings from this research do not support a correlation between parents' participation in home-based, school-related activities and their support of parent-teacher Facebook communication.

Table 2

Descriptive Statistics for Chi-Square Analysis: Facebook Support by Home Involvement

\begin{tabular}{lrrr}
\hline Activity & df & Phi & $p$ \\
\hline Supervise homework & 8 & 0.416 & 0.316 \\
Help with homework & 8 & 0.338 & 0.627 \\
Talk about school day & 8 & 0.264 & 0.709 \\
Work on activities that support learning & 8 & 0.398 & 0.885 \\
\hline
\end{tabular}

*Significant difference at .05

Based on the findings, it appears there is no association between parent support of teacher contact via Facebook and parent engagement in school-based activities. 


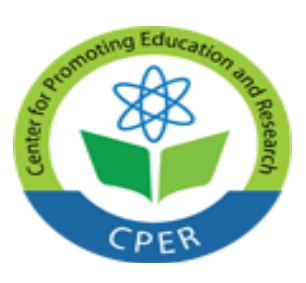

\section{Discussion}

Parent involvement remains one of the biggest problems facing educators today. This issue is exacerbated by ineffective communication, which has negatively influenced relationships between schools and families. Undeniably, communication is critical to garnering parent participation in school-related activities at school and at home (Graham-Clay, 2005; Sanders et al., 1999). Despite having access to more advanced communication tools than any other period in history, educators largely have not varied their parental outreach strategies to match the needs and interests of parents. This mismatch of communication preferences results in a mismatch of perspective between teachers who may feel parents are apathetic, and parents who may believe that they never directly receive invitations seeking their involvement (Halsey, 2005).

Social media provides the opportunity for parents to be involved in the educational process anytime of the day from any web-connected device. These tools have become increasingly necessary to reach a growing segment of parents who have abandoned traditional modes of communication (Shein, Wilson, \& Keelan, 2011). Through social media, teachers and parents can build relationships and come together in a way that resembles community (Davis, Deil-Amen, Rios-Aguilar, \& Canche, 2012). This analysis focused on parental communication preferences and the relationship between parents' support for parent-teacher Facebook interaction and their participation in schoolfocused activities at home.

Communication preferences varied with parents indicating their preferences for both traditional and nontraditional methods of communication. Based on these results, Facebook was reported as parents' least preferred method of communication with teachers. This was surprising due to the large \%age of parents (70\%) who had Facebook accounts. Moreover, among the study population, those with Facebook accounts were fairly active users. Respondents reported logging on Facebook multiple times a day, for various lengths of time, for various purposes. Since parents spend a great deal of their time on social media anyway, it seemed that connecting with their child's teachers while using those sites would be a reasonable activity.

Junco (2011) indicated that not only was the extent to which participants engaged in social media important, but the types of activities in which they were involved were critical as well. Users' activities while on social media determine whether their social presences offered them a sense of community that would mimic what they could experience in the offline world. For many study participants, their primary usage of Facebook was to connect with individuals with whom they already had relationships. This phenomenon has been supported by literature. Nadkarni and Hofmann (2012) suggested that Facebook usage was motivated by two primary needs - the need to belong and the need for self-presentation. Perez-Latre (2011) suggested that social networks reinforce existing relationships that forge greater connections between users' online and offline worlds. Steinfield and Lampe (2007) also agreed that Facebook was used to a greater degree to strengthen offline friendships than to meet new people.

Study participants purportedly had poor relationships with their child's teachers, as they cited infrequent communication and seldom received suggestions on how they could help support their child in school. The majority of parents indicated they never received invitations to come to their child's classroom and many indicated they were never personally contacted to discuss their child's performance. Communication between study participants and teachers was institutional, as opposed to personalized in nature. Families were disconnected from meaningful relationships with the school as well. Largely, parents were not part of the decision making processes regarding the school governance as they rarely volunteered, raised money for, and participated in parent advisory board meetings. Perhaps if parents had stronger relationships and more frequent communication with school personnel, they would have been more willing to utilize Facebook as a means of communication with teachers.

On account of the plethora of barriers to school-based parental involvement (e.g. work obligations, not receiving timely information, etc.), the assumption was that parents who preferred Facebook communication with 


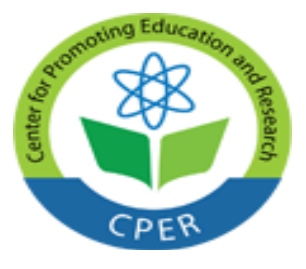

teachers would be more likely to be involved in school-related activities at home. Half of the sample confessed that work obligations usually or always kept them from participating in school-based activities. More than three-fourths of the sample stated that events at the school were usually or always scheduled at times they could not attend. The asynchronous nature of Facebook, as Bryant and Marmo (2010) pointed out though, enables users to connect at times that are most convenient for them. In this regard, social media offers a non-traditional, two-way communication tool that can facilitate greater parental involvement in the educational process by eliminating timespecific and located-based interaction.

Facebook communication could also serve as a buffer for parents who were reluctant to come to the school because of their own negative school experiences and their perceived and real academic inadequacies due to the complexity of the curriculum. Baskwill (2013) added that parents are more likely to be on Facebook every day as opposed to visiting a teacher-created blog or website occasionally only after being reminded to do so. Also, most parents are already familiar with Facebook and would not need to learn how to use the platform in order to communicate with teachers.

\section{Limitations}

There were several limitations to this research. Findings from this study may not be generalizable as a result of the small sample size and the non-probability sampling techniques utilized. The sample size was not representative of the larger school population as study respondents were more diverse with regard to their racial and educational backgrounds. Moreover, this study utilized a traditionally ineffective method of dissemination sending materials home through students - to solicit participation in the study. In other words, the study used a pencil and paper data collection method to find out about respondents' inclination to participate in web-based communication via social media. Therefore, there may be overrepresentation of individuals who prefer non-electronic forms of communication with school personnel in the sample population. Other parents simply may not have received the study materials because their child intentionally or unintentionally neglected to give them the information.

Finally, the study only asked about parental preferences regarding one social media platform. This may not have revealed respondents who are amenable to social media communication with their child's teachers through other platforms such as LinkedIn or Twitter. Also, the study did not ask respondents about the types of teacherparent Facebook communication they would be willing to support. Kane et al., (2014) maintained that relationships on social media are limited to friend or follower. The group feature within social media sites, however, allows users to interact and share information without revealing their private profiles. Essentially, social media sites are privacyinvading forms of communication in nature, as users must disclose information in order to create profiles on these sites. Based on the study findings, parents may believe that communicating via Facebook violates professional boundaries. Parents may be more willing to support Facebook interaction with teachers via class-specific groups and fan pages, which in the absence of connecting as "friends" on the site, would limit the private content (e.g. photos, videos, status updates) that would be revealed to teachers based on their privacy settings. It is possible that some parents would have been in favor of specific activities that did not require them to reveal their online identity. More than $60 \%$ of online adults restrict access to their social media pages so that only friends can see their profiles (Madden, 2012).

\section{Future Research}

Few studies examine parental communication preferences. Even fewer studies, if any, address parent-teacher communication via social media. While there is some research that exists on students' and teachers' usage of social media and their communication preferences, K-12 have not yet fully recognized how to leverage these tools to enhance teaching and learning. Until researchers provide empirical evidence that demonstrates the positive impact 


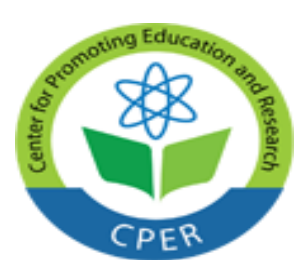

of these tools on academic achievement and parental involvement, the role of social media in education will remain unclear. Suggestions for future research include the following:

Additional research efforts should be directed to explore educators' reluctance to appropriately use social media to develop relationships between schools and families. Without the support of the education community, school-family communication via social media will not take place.

This study only asked parents about their willingness to be contacted by their child's teachers via Facebook. Future research should be conducted to determine which social media tool (Facebook, Twitter, LinkedIn, or Pinterest), if any, would be most effective to connect with families.

Additional studies may be conducted to ascertain the types of social media interaction parents would support such as participation in a group, messaging, and chats.

This study included respondents from one high school in south suburban Chicago. The study could be expanded to include multiple schools throughout metropolitan Chicago to gain a greater understanding of parents' communication preferences and the appropriateness of using social media to contact parents across the region.

\section{Conclusion}

Technological advances, especially as it relates to social media, have transformed the practices and behaviours of professionals in nearly every industry known to man. Social media has revolutionized the manner in which we communicate both personally and professionally. In the field of education, however, this statement does not necessarily hold true. Discussions regarding strategies to integrate social media in instructional practices only began six years ago. The Center for Excellence in Teaching and Learning of Southern University, established in 2009, was founded to integrate the use of innovative pedagogical methods (Ralph \& Ralph, 2013). Since then, schools across the nation have gone from outright banning the use of mobile telephones and social media sites labelling these tools as distractions to allowing their limited use during specific times for specific purposes.

Social media offers the opportunity for parents and teachers to connect asynchronously or synchronously, enabling greater participation in the educational process for families with working schedules and those who prefer school-home communication via electronic means. However, in the field of elementary and secondary education, the role of social media both in and out of the classroom remains debatable. Existent research has not yet definitively provided empirical evidence that supports the effectiveness of school-home communication via social media. This quantitative analysis established research questions related to parents' communication preferences and their involvement in school-related activities at home via the use of social media.

\section{References}

Adams, W., Infeld, D., \& Wulff, C. (2011). Statistical software for curriculum and careers. Journal of Public Affairs Education, 19(1), 173-188.

Baskwill, J. (2013). Attention grabbing tools for involving parents in their children's learning. Portland, ME: Stenhouse Publishers.

Bokony, P., Whiteside-Mansell, L., Swindle, T. (2013). Family map inventory and TIPS for great kids!: Tools for increasing parent-teacher communication. Dialog, 16(1), 183-188.

Bridgemohan, R., van Wyk, N., \& van Staden, C. (2005). Home-school communication in the early childhood development phase. Education, 126(1), 60-78. 


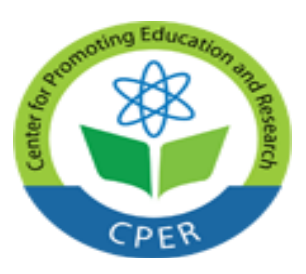

VOL: 5, ISSUE: 2

February/2019

https://ijbassnet.com/

E-ISSN: 2469-6501

(C) Center for Promoting Education and Research (CPER) USA

WwW.cpernet.org

Bryant, E. \& Marmo, J. (2010). Relational maintenance strategies on Facebook. College Student Journal, 47(1), 113-121.

Coyne, A. (2015, July 23). Social media deserves role in emergency planning, study shows. GreenvilleOnline. Retrieved from http://www.greenvilleonline.com/story/money/business/2015/07/23/social-media-deserves-roleemergency-planning-study-shows/30562519/

Cuban, L. (2001). Oversold and underused: Computers in the classroom. Cambridge, MA: Harvard University Press.

DePlanty, J. Coulter-Kern, R., \& Duchane, K. (2007). Perceptions of Parent Involvement in Academic Achievement. Journal of Educational Research, 100(6), 361-368.

Epstein, J. L. (2001). School, family, and community partnerships: Preparing educators and improving schools. Boulder, CO: Westview Press.

Ferriter, W. (2011). Digitally speaking: Using social media to reach your community. Educational Leadership: The Effective Educator, 68(4), 87-88.

Graham-Clay, S. (2005). Communicating with parents: Strategies for teachers. School Community Journal, 16(1), 117-129.

Green, C., Walker, J., Hoover-Dempsey, K., Sandler, H. (2007). Parents' motivations for involvement in children's education: An empirical test of a theoretical model of parental involvement. Journal of Educational Psychology, 99(3), 532-544. doi: 10.1037/0022-0663.99.3.532

Halsey, P. (2005). Parent involvement in junior high schools: A failure to communicate. American Secondary Education, 34(1), 57-69.

Haspels, M. (2008). Will you be my Facebook friend? Paper presented at the $4^{\text {th }}$ Annual GRASP Symposium, Wichita, KS: Wichita State University.

Hosman, L. \& Cvetanoska, M. (2013). Technology, teachers, and training: Combining theory with Macedonia's experience. International Journal of Education and Development using Information and Communication Technology, 9(3), 28-49.

IACP Center for Social Media. (2015). Fun facts. Retrieved from http://www.iacpsocialmedia.org/Resources/FunFacts.aspx

Kane, G., Alavi, M., Labianca, G, \& Borgatti, S. (2014). What's different about social media networks? A framework and research agenda. MIS Quarterly, 38(1), 275-304.

Kaplan, A. \& Haenlein, M. (2010). Users of the world, unite! The challenges and opportunities of social media. Business Horizons, 53(1), 59-68. doi:10.1016/j.bushor.2009.09.003

Kotrlik, J. \& Redmann, D. (2009). Technology adoption for use in instruction by secondary technology education teachers. Journal of Technology Education, 21(1), 44-59.

Lewis, B. (2010). Social media and strategic communication: Attitudes and perceptions among college students. Public Relations Journal, 4(3). 


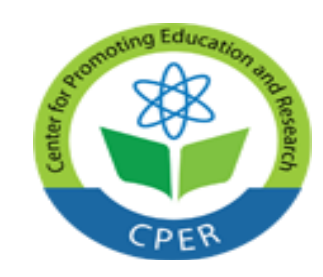

VOL: 5, ISSUE: 2

February/2019

https://ijbassnet.com/

E-ISSN: 2469-6501

(C) Center for Promoting Education and Research (CPER) USA

WWW.cpernet.org

Madden, M. (2012). Privacy management on social media sites. Pew Internet. Retrieve

from http://pewinternet.org/Reports/2012/Privacy-management-on-social-media.aspx

Martinez-Aleman, A. (2014). Social media go to college. Change: The Magazine of Higher Learning, 46(1), 13-20. doi: $10.1080 / 00091383.2014 .867203$

Moran, M., Seaman, J., \& Tinti-Kane, H. (2011). Teaching, learning, and sharing: How today's higher education faculty use social media. Babson Survey Research Group. Retrieved from

http://files.eric.ed.gov/fulltext/ED535130.pdf

Mourlam, D. (2013). Social media and education: Perceptions and need for support. Journal on School Educational Technology, 9(3), 23-28.

Nadkarni, A. \& Hofmann, S. (2012). Why do people use Facebook? Personality and Individual Differences, 52(3), 243-249.

Ouimette, M., Feldman, J., \& Tueng, R. (2006). Collaborating for high school student success: A case study of parent engagement at Boston Arts Academy. School Community Journal, 16(2), 91-114.

Oxley, D. (2013). Connecting secondary schools to parents and community. Principal's Research Review, 8(1), 1-7.

Pew Research Center. (2014). Mobile technology fact sheet. Retrieved from http://www.pewInternet.org/factsheets/mobile-technology-fact-sheet/

Ranieri, M. Manc, S. \& Fini, A. (2012). Why (and how) do teachers engage in social networks? An exploratory study of the professional use of Facebook and its implications for lifelong learning. British Journal of Educational Technology, 43(5), 754-769.

Rutherford, C. (2010). Facebook as a source of informal teacher professional development. In Education, 16(1).

Sanders, M, Epstein, J., \& Connors-Tadros, L. (1999). Family partnerships with high schools: The parents' perspective. Baltimore, MD: Center for Research on the Education of Students Placed At Risk, Johns Hopkins University.

Silverstein, J. (2015, June 12). Texas teacher's Facebook rant about McKinney pool party gets her 'relieved of her duties': report. New York Daily News, Retrieved from http://nydn.us/1MNvMaF

Smith, A. (2012, November 30). Part III: The impact of mobile phones on people's lives. Pew Research Center. Retrieved from http://www.pewinternet.org/2012/11/30/part-iii-the-impact-of-mobile-phones-on-peoples-lives/

Tyson, J. (2009). Connecting through Facebook: The influence of social networking on Communication. Retrieved from https://wakespace.lib.wfu.edu/bitstream/handle/10339/14774/jtyson_Thesis.pdf

UChicago Impact. (n.d.). 5Essentials. Retrieved from https://uchicagoimpact.org/5essentials

University of Phoenix. (2014). K-12 teachers uncertain about how to connect with students and parents via social media, reveals University of Phoenix study [Press release]. Retrieved

from http://www.phoenix.edu/news/releases/2014/01/new-survey-shows-teachers-uncertain-on-social-media.html

Wagner, M. (2015, June 11). Florida high school principal sacked for defending McKinney pool party cop. New York Daily News. Retrieved from http://nydn.us/1B8MVKh 